\title{
RECUERDOS PLURALES \\ DE UNA BREVE DIRECCIÓN
}

\author{
Clara E. LidA \\ El Colegio de México
}

$\mathrm{H}$

ace poco más de 30 años, en enero de 1989, asumí la dirección de Historia Mexicana, a solicitud de mi colega, Alicia Hernández Chávez, quien poco antes había sido designada directora del Centro de Estudios Históricos ( $\mathrm{CEH}$ ), de El Colegio de México. Este nombramiento se daba en un contexto de desencuentros que, desde hacía algunos años, creaban un clima de cierta tirantez. En ese contexto, la revista había quedado acéfala. Cuando se me pidió que asumiera dicha función, yo tenía plena convicción de que todos debíamos aceptar las labores que se nos requirieran en apoyo de la institución. Por ello acepté hacerme cargo, pero no sin muchas vacilaciones, pues dirigir la revista no había estado en mi horizonte de intereses.

Por otra parte, yo no me consideraba entonces - ni hoy- una estudiosa de la historia de México, aunque por interés personal y obligaciones docentes desde mis años en Estados Unidos, conocía más o menos bien la época independiente. Por otra parte, ya había tenido experiencias previas que me habían familiarizado con las labores editoriales de revistas académicas y que me permitían asumir una responsabilidad editorial sin que ello fuera terra incognita. Sin embargo, mi compromiso fue aceptar 
de manera provisional, mientras se pensaba en otra persona más afín a la historiografía mexicanista.

Antes de dar una respuesta definitiva a dicha invitación, una de mis preocupaciones fue recorrer los números publicados hasta entonces y hacerme una idea más clara de la revista. Historia Mexicana se creó en 1951, como una publicación independiente. Con esto quiero decir que Daniel Cosío Villegas, su fundador, nunca concibió esta revista como órgano de difusión exclusivo de un centro ni como una publicación al servicio de un pequeño grupo colegial, sino como una revista especializada de El Colegio, abierta a las mejores plumas y cabezas en el campo, fuera cual fuera su origen institucional y nacional. Además, la revista no estuvo atada a los hilos ideológicos o metodológicos de ninguna doctrina o escuela, sino que se abrió a todos los aires que oxigenaban el conocimiento histórico. Se trataba de garantizar la calidad y la independencia y no de subordinar el trabajo intelectual a intereses particulares.

Por otra parte, una revista de la talla de Historia Mexicana se había propuesto observar ciertas reglas tácitas, pero evidentes: obtener las mejores colaboraciones dentro de la disciplina, mantener las normas y pautas más estrictas en la selección de las colaboraciones aceptadas, fomentar la riqueza y multiplicidad de enfoques -sin sectarismos ni chauvinismos-, y buscar los enfoques y perspectivas que contribuyeran al diálogo más abierto, más amplio y más enriquecedor. El objetivo era simple: publicar trabajos sólidos, novedosos, originales, sustentados en una investigación rigurosa que contribuyera a renovar la disciplina. Éstas fueron las lecciones del pasado que quise recoger entre 1989 y 1991, al aceptar hacerme cargo de la dirección de la revista.

Mi acuerdo con la directora del Centro tuvo varias vertientes. Por un lado, con los años, la dirección de Historia Mexicana se 
había vuelto una labor relativamente unipersonal, que dependía muy directamente de las decisiones e intereses del director en turno. Desde luego, esto le imprimía un carácter muy individual a una revista que, en mi experiencia y nutriéndome de su historia, se beneficiaría más de un cuerpo colectivo de redacción, que abriera la publicación a diversas ópticas, temas e intereses. En este sentido, propuse nombrar un Consejo Asesor anual, al margen del Comité interno del CEH. Mi idea es que dicho Consejo estuviera compuesto por colegas de diversas latitudes, y no exclusivamente de casa, que ayudaran con sus consejos a mejorar los contenidos, que solicitaran colaboraciones y recomendaran a los mejores especialistas para evaluar los artículos. Por razones largas de explicar aquí, la idea de un consejo internacional no fue enteramente posible, aunque luego se sumaron nuevos colegas recién contratados, entre los cuales había varios nombres con amplios intereses internacionales que comenzaban a cambiar el rostro del Centro y de la revista. Años después, se retomó la idea y se pudo establecer un Comité Internacional.

Una segunda propuesta era introducir algunas novedades, como la creación de una sección que estimulara el debate historiográfico, tan raro en el mundo hispánico. Esto lo inauguramos en el número 155, de enero-marzo de 1990, con un artículo de Enrique Florescano sobre el mito como elemento para reinterpretar la historia mesoamericana, que debatieron Alfredo López Austin, Pedro Carrasco y Georges Baudot y replicó el propio Florescano. Sin embargo, la idea de una sección de debate no prosperó como yo hubiera esperado y este planteamiento decayó. También había anticipado que hubiera una apertura a la historia comparada, que situara a México en su hábitat histórico por antonomasia: Latinoamérica, o incluso más universal, cuando el tema y el enfoque lo requirieran. Sabía que algunos no apreciaban este giro, pero la historia no podía estar encerrada sin salir de las fronteras.

Siguiendo la idea anterior, de abrir la dirección y la revista a un diálogo más amplio y menos personal, también propuse 
crear la figura de Redactor, que rotara periódicamente, para que hubiera un segundo de a bordo en la dirección, pensando en cuánto más enriquecedor para el mejor funcionamiento de la revista sería poder consultar dudas y problemas de la redacción con un colega informado y atento. Por ello, y considerando mi poca familiaridad con la época colonial, propuse que la doctora Dorothy Tanck de Estrada, quien estudiaba diversos aspectos de la época virreinal novohispana, fuera Redactora. Un año y medio después, este puesto rotó y el doctor Manuel Miño Grijalva, también especialista en los siglos coloniales, se hizo cargo como Redactor. Ambos fueron de un apoyo invaluable, que nunca dejaré de agradecer.

También me interesaba que, periódicamente, se pudieran publicar números monográficos a cargo de especialistas en cada tema. De hecho, en 1983, en el número 129, había aparecido un dossier armado por mí sobre "La sociedad capitalina en el Porfiriato", con los trabajos que sobre el tema habían desarrollado y reelaborado cinco estudiantes de mi seminario: M. Ceballos, J.-P. Bastian, R. Sordo, P. Santoni y S. Bryan, lamentablemente fallecida poco tiempo después. Ese dossier sufrió un curioso traspié, pues apareció sin la "Presentación” inicial que yo había preparado. Al indagar al respecto, se me dijo que seguramente el texto se había traspapelado entre su llegada al escritorio de la secretaria y la imprenta.

La experiencia anterior me dio pie para pedir a la dirección del Centro que la revista tuviera un asistente de la revista, para dar un seguimiento cercano a todos los materiales que entraban y salían de la redacción hasta su publicación final. Así comenzó a trabajar en Historia Mexicana Beatriz Morán Gortari, quien ya había sido una excelente becaria mía, y que hoy está a cargo de la Redacción. Además, solicité que la revista tuviera una computadora, para que así todo el material que se recibiera y enviara estuviera digitalizado y siempre hubiera un respaldo y un resguardo. Esto, que hoy podría parecer una solicitud 
redundante, no lo fue entonces e, incluso, en algún momento se convirtió en un motivo de discordia. Pero lo cierto es que, en el Centro de Estudios Históricos en 1989, no había una sola computadora y en todo El Colegio, éstas no alcanzaban la decena. Es decir, era un pedido inusitado, ante el cual me pusieron reparos presupuestales y otros. Dada mi insistencia, sin embargo, la dirección finalmente negoció con la presidencia para que se otorgaran fondos para comprar más aparatos y pudiéramos todos tener la fiesta en paz, para gran alegría, sobre todo, de la secretaria, Sara Reséndiz, la inolvidable Sarita. Así comenzó la digitalización en el CEH.

Si éstos fueron algunos de los cambios que pude ir implementando entre enero de 1989 y junio de 1991 (desde el número152 hasta el 161), también hubo momentos difíciles, que revelan las dificultades que surgen al querer introducir transformaciones después de años de rutina.

Un primer problema apareció cuando asumí la dirección y me encontré con que mi antecesor no había dejado ninguna reserva de artículos para publicar, cosa inusitada en una revista de estas características. Había un número en prensa y eso era todo. Puesto que un requerimiento esencial de toda revista es la periodicidad, mi mayor preocupación fue cómo evitar un retraso y mantener la revista al día. Afortunadamente, en febrero de 1989, Silvio Zavala, fundador del CEH, tercer presidente de El Colegio, historiador de enorme prestigio y maestro de muchas generaciones de estudiantes, cumpliría 80 años. Era natural pensar en hacerle un homenaje entre colegas y exalumnos destacados, por lo cual de inmediato comencé a solicitar colaboraciones aquí y allá. La respuesta fue tal, que en poco tiempo pudimos publicar no uno, sino dos números (152 y 153). Salvada esta crisis, pude seguir buscando y recibiendo artículos de manera sistemática. 
A poco de comenzar en la revista, sucedió un incidente profundamente desagradable. Un día recibí una llamada urgente de un estudiante, pidiéndome en nombre de sus compañeros que lo recibiera a la mayor brevedad. Era tal el tono de urgencia, que lo cité de inmediato y llegó con un ejemplar de El Heraldo de México, periódico que yo no conocía. En él, un columnista, cuyo nombre no vale la pena recordar, atacaba a la dirección del CEH por haber nombrado como directora de Historia Mexicana a una extranjera, ajena a la historia del país. El ataque xenófobo se dirigía, en concreto, contra mí, por no ser mexicana, y contra Alicia Hernández, por haberme nombrado y, además, por contratar a otros extranjeros en el CEH, puesto que, en efecto, la directora había comenzado a renovar la planta docente con colegas de prestigio internacional, fueran mexicanos o no.

No pasaron muchas horas antes de que me llegara otra llamada urgente, esta vez de Silvio Zavala, quien me pidió que lo fuera a ver cuanto antes. Don Silvio, que había sido mi profesor y me tenía aprecio, me explicó que había leído el artículo y que había hecho algunas averiguaciones, por lo cual sabía que un puñado de colegas, cuyos nombres tenía pulcramente anotados, estaban detrás de ese "periodicazo". Su intención era hablar con el entonces presidente de El Colegio, pues según él, "unas manzanas podridas podían pudrir todo el barril”. Me consta que así lo hizo, pero también que la presidencia prefirió "no hacer olas". Lo inesperado fue que las olas se siguieron haciendo porque, ya puesto a ello, el mismo columnista publicó dos artículos más, no solo contra mí, sino también contra otros colegas extranjeros recién contratados en el Centro, acusando a todos de recibir pagos extras "por debajo de la mesa", insinuando corrupción. Todo resultaba tan obviamente malintencionado, que sin duda lo mejor era hacer caso a lo sugerido por la presidencia, no responder a infundios. Al cabo de los años, es afortunado ver que, desde entonces, ha habido varios extranjeros dirigiendo Historia Mexicana. 
Para mí era importante que la revista saliera adelante y bien. Habíamos tenido algún desacuerdo con el Departamento de Publicaciones de El Colegio, a causa de algunas negligencias en la impresión y por tomar decisiones unilaterales respecto del formato, así como por traducciones descuidadas y mala revisión de galeras, lo cual se solucionó cuando Beatriz Morán participó en ello activamente. Estas dificultades se fueron resolviendo y la calidad en la presentación de la revista recuperó mejores épocas. Que eso era así, se podía confirmar por la abundante recepción de artículos con dictámenes positivos que iban conformando la reserva para los siguientes números, por las buenas opiniones recibidas y por el aumento en ventas y canjes que realizaba la institución.

Sin embargo, eso tuvo su lado difícil, porque a medida que la revista salía adelante, la Dirección del Centro quiso participar en las decisiones de la redacción y aparecer a la cabeza de la publicación. Como ya lo señalé, esto es algo que, desde su fundación, Cosío Villegas había tenido muy en cuenta: la independencia de los quehaceres de la publicación de aquellos de otras instancias directivas del Centro y de El Colegio, precepto que defendí con firmeza, pero que me dio la pauta para ir poniendo fin a esas labores.

A mediados de 1991, cuando se cumplían 40 años de la aparición del primer número y la publicación avanzaba ya sin tropiezos, yo tenía claro que mi función había concluido y así lo expresé en la presentación del número 161, titulada "Hacia la quinta década". Al cabo de dos años y medio dejaba la revista con resultados dignos y, para mi alegría, quedaba en las excelentes manos de mi apreciada colega, la doctora Josefina Z. Vázquez. 
